Document downloaded from:

http://hdl.handle.net/10251/99168

This paper must be cited as:

Vona, A.; Di Martino, F.; García-Ivars, J.; Picó, Y.; Mendoza Roca, JA.; Iborra Clar, MI. (2015). Comparison of different removal techniques for selected pharmaceuticals. Journal of Water Process Engineering. 5:48-57. doi:10.1016/j.jwpe.2014.12.011

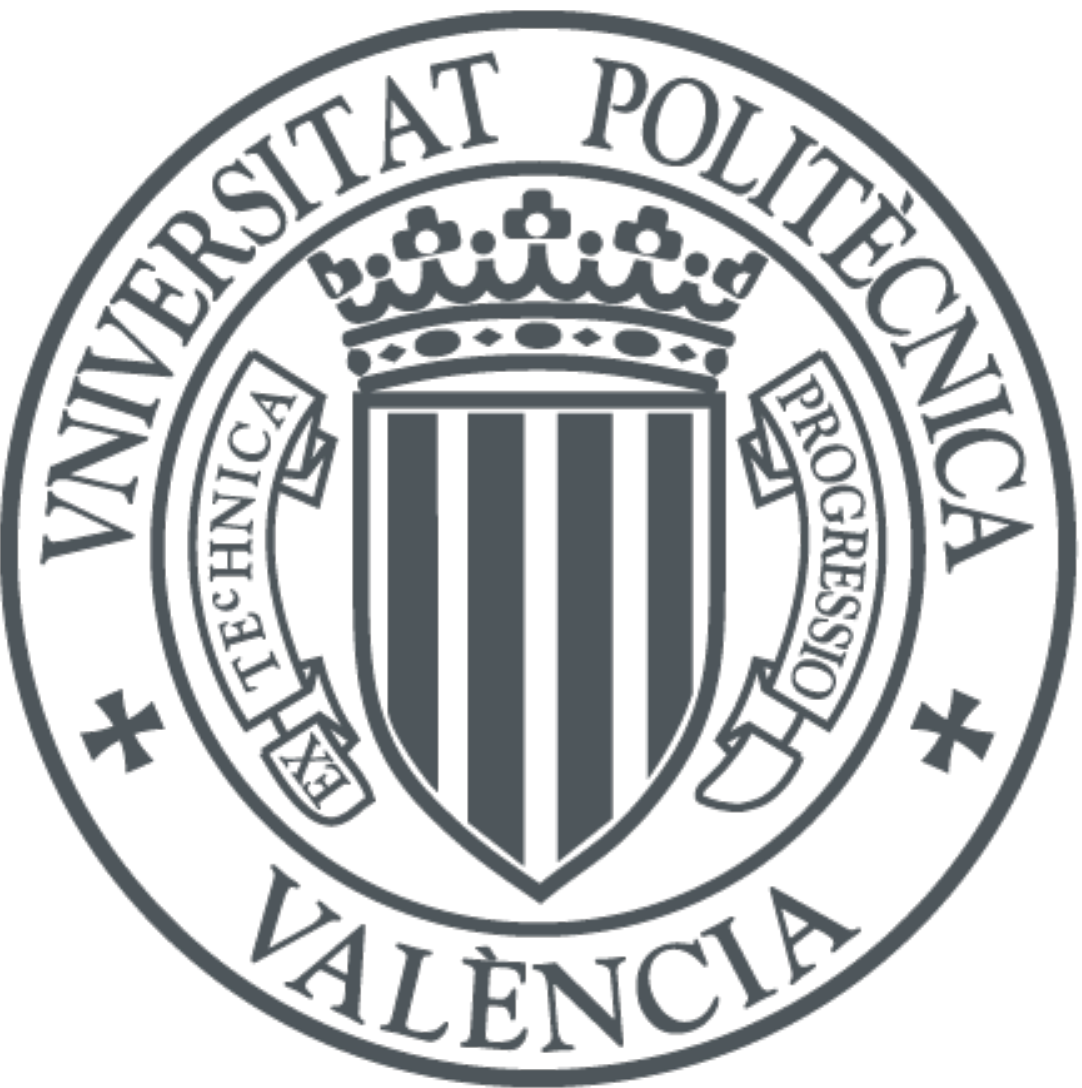

The final publication is available at

http://dx.doi.org/10.1016/j.jwpe.2014.12.011

Copyright Elsevier

Additional Information 


\section{Comparison of different removal techniques for selected pharmaceuticals}

2 Andrea Vona ${ }^{1}$, Francesco di Martino ${ }^{1}$, Jorge Garcia-Ivars²*, Yolanda Picó ${ }^{3}$, José-Antonio Mendoza-Roca ${ }^{1-2}$,

3 Maria-Isabel Iborra-Clar ${ }^{1-2}$.

$4 \quad{ }^{1}$ Department of Chemical and Nuclear Engineering, Universitat Politècnica de València, C/Camino de Vera 5 s/n, 46022 Valencia, Spain

$6 \quad{ }^{2}$ Research Institute for Industrial, Radiophysical and Environmental Safety (ISIRYM), Universitat

7 Politècnica de València, C/Camino de Vera s/n, 46022 Valencia, Spain

$8 \quad{ }^{3}$ Laboratori de Nutrició i Bromatologia, Facultat de Farmàcia, Universitat de València, Av. Vicent Andrés

9 Estelles s/n, 46100 Burjassot (València), Spain

Tel. +34 963879633

Fax. +34963877639

Correspondence to: Jorge Garcia-Ivars (E-mail: jorgariv@posgrado.upv.es)

\section{ABSTRACT}

Recently, there is an emergence of endocrine-disrupting compounds, pharmaceuticals, and personal care products (EDC/PPCPs) as important pollutants to remove from drinking water and reclaimed wastewater. In this work, the efficiency of removing pharmaceuticals (PCs) from model aqueous solutions and raw wastewater with ultrafiltration (UF), nanofiltration (NF), activated carbon adsorption (AC), biological methods (SBR) and oxidation with $\mathrm{ClO}_{2}$ was investigated. Some treatments have also been used as combined processes: $\mathrm{UF}+\mathrm{NF}, \mathrm{UF}+\mathrm{AC}, \mathrm{SBR}+\mathrm{ClO}_{2}$. Ibuprofen, Acetaminophen, Diclofenac, Sulfamethoxazole, Clonazepam and Diazepam were selected as model compounds. In order to evaluate their removal, PC solutions were also considered at several operating conditions ( $\mathrm{pH}$, conductivity, concentration, temperature), and optimal conditions were obtained. Experiments were performed at usual PC concentrations in wastewaters: $1000 \mathrm{ng} / \mathrm{L}$ for Ibuprofen and Acetaminophen, 300 ng/L for Diclofenac, Sulfamethoxazole, Clonazepam, and Diazepam. Separation was evaluated by liquid chromatography-mass spectroscopy. Results indicated that the removal efficiency depends on their Log Kow, which is intrinsically related to 
their hydrophobicity and then, to their adsorption onto the surface (UF, NF and AC). Also, NF, AC and combined processes (UF+NF, UF+AC) were the most suitable separation techniques to obtain high removal efficiencies for most of the PCs used, except for Acetaminophen (which showed great removal efficacy using SBR). UF presented low removal yields for all PCs tested. $\mathrm{ClO}_{2}$ treatment was more effective at high concentration $(50 \mathrm{mg} \mathrm{ClO} / \mathrm{L})$. Furthermore, results also showed that there are significant differences on the performance of the processes applied and which treatment is the most effective for each PC analyzed.

KEYWORDS: Pharmaceutical compounds, membrane processes, activated carbon, environmental analysis, hybrid process.

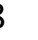

9

\section{INTRODUCTION}

The presence of pharmaceuticals and personal care products (PPCPs) in the environment is recognized as emerging issue due to their negative environmental and human health effects [1]. Pharmaceuticals (PCs) are introduced into the environment from discharges of wastewater treatment plants (WWTPs), which are not designed to treat all these substances and thus, they cannot be completely removed [2]. In this way, these effluents from WWTPs are relevant pollutant sources for the environment. Although PCs are present at very low concentrations $(\mu \mathrm{g} / \mathrm{L}$ to ng/L range), they may cause environmental and health hazards [3]. Antimicrobial agents are the most widely used. As a major consequence, this usage could generate antibiotic-resistant bacteria, especially in quinolones and sulphonamides [4].

Furthermore, the application of sewage sludge to soils may be a potential route for these PCs to reach the terrestrial environment and then, the human food chain. In that way, it is not surprising that these antibiotics were detected even at subinhibitory concentrations in surface and groundwaters, treated wastewater, biosolids, soils, and sediments [5]. Removal efficiency for PCs at WWTPs depends on biological treatments [6], of which activated sludge process is the most 
frequently used. Although some promising technologies have been implemented, more studies are required to develop really effective treatments, especially for the most persistent chemicals.

A combination between membrane filtration processes and biological treatment replaces advantageously a secondary clarification and tertiary steps. Ultrafiltration (UF) is used in wastewater treatment and drinking water production to remove natural organic matter (NOM) and micropollutants, such as pesticides and PCs $[7,8]$. In addition, these previous studies investigated different separation mechanisms (size/steric exclusion, hydrophobic adsorption, and electrostatic repulsion, among others). Recently, other membrane processes have been evaluated to remove PCs from wastewater. Nanofiltration (NF) has been used to successfully remove low-molecular-weight organic compounds such as pesticides, endocrine disruptors, and various PCs during water treatment [8-10]. This removal can occur through multiple mechanisms. At the beginning of the filtration process, removal can be governed by the adsorption phenomenon of different contaminants with hydrophobic nature or strong hydrogen-bonding characteristics [11-14]. Examples of this kind of contaminants are 2-naphthol, estrone, and non-phenolic pesticides. In many cases, removal can also occur through steady-state rejection. This may be due to steric effects for uncharged solutes or the combination of steric and electrostatic effects for charged solutes. These rejection mechanisms can affect different water-quality parameters including $\mathrm{pH}$, ionic strength, and organic content [15].

The removal of PCs by adsorption is one of the most promising techniques. Adsorption process using activated carbon (AC) is frequently applied for removing natural or synthetic organic compounds (OCs) in drinking water treatment [16]. This process has numerous advantages: applicability at very low concentrations of pollutants, ease of operation, suitable for batch and continuous processes, possibility of regeneration and reuse, and low capital cost [17]. AC is a useful adsorbent to remove PCs due to its high surface area, high degree of microporosity, and welldeveloped surface chemistry properties. AC surface is predominantly hydrophobic but may also 
contain functional groups formed during the activation process. These groups mainly contain oxygen and hydrogen, but they may also contain chlorine, nitrogen, and sulphur. The nature of these functional groups depends on activation conditions, which contribute to the acidic/basic character of the adsorbent surface and thus, it has influence on specific interactions with adsorbed compounds [18]. It has been demonstrated that the presence of oxygen-containing functional groups on the surface and their concentration levels play an important role in adsorption capability and removal mechanism [19-21]. Other important AC properties are: pore size distribution [20,22], ash content [23], and pH of point of zero charge (pHPZC), as an indicator of AC surface chemistry [24]. AC can be produced from several carbonaceous materials, including wood, coal, lignin, and coconut shells [25]. Recent studies have reported excellent performance of low cost ACs for the removal of pharmaceutical compounds, which is an attractive and economic alternative for water treatment along with waste disposal and recycling [24]. AC can be commonly found in two different forms: powdered activated carbon (PAC) and granular activated carbon (GAC). Several authors demonstrated the efficiency of both ACs (PAC and GAC) in the removal of organic micropollutants from water $[26,27]$. Since PAC is dynamically added to the plant, it can be used seasonally to treat wastewater in which the risk of OCs traces could be great (e.g., low-flow events). The capability of PAC to remove OCs depends on the PAC dose and the contact time, as well as the target contaminant properties (e.g. water solubility, hydrophobicity, charge, polarizability, size, aromaticity and the presence of specific functional groups) [20,28]. GAC used in packed bed filters was also highly effective. However, more hydrophilic contaminants can break the GAC filter much more rapidly than strongly bound hydrophobic contaminants. Therefore, in both powdered and granular forms, AC demonstrates a great potential for removal OCs traces, although PAC dose and GAC regeneration/replacement are two critical parameters to be considered for obtaining a successful removal [28]. Generally, loaded GAC is regenerated ex situ by heating [29] or steaming [30]. After several regenerations, GAC is managed as a waste and is incinerated [31]. 
Other interesting technique to remove PCs is using a Sequencing Batch Reactor (SBR), which is based on the principles of the activated sludge process. In a SBR, oxygen is bubbled through the wastewater to reduce biochemical oxygen demand (BOD) and chemical oxygen demand (COD). After that, the effluent is suitable to be discharged to surface waters or to be used in agriculture. The operation cycle is divided into five phases: filling, aeration-reaction, settling, decantation and idle. SBR has been successfully employed in the treatment of both municipal and industrial wastewater [32]. Moreover, it has been demonstrated that SBR is valid as a system to remediate polycyclic aromatic hydrocarbons (PAH) contaminated sediments, while offering a high flexibility to adapt the process to the characteristics of the compounds to be treated. For instance, if the value of the volumetric exchange ratio could be properly controlled, it would be possible to limit the pollutant load of the biomass in the SBR. So, it could be avoided the inhibition phenomena [33].

Additional chemical oxidation step can be used in WWTPs if the pollutants are not completely removal by biological treatment [34,35]. Among the chemical oxidants used in wastewater treatment, chlorine dioxide $\left(\mathrm{ClO}_{2}\right)$ is an interesting compound due to its potential to remove PCs in wastewater. The application of $\mathrm{ClO}_{2}$ to remove PCs from drinking water, surface water and wastewater effluents has shown promising results. The non-steroidal anti-inflammatory drug Diclofenac, reported as one of the most frequently detected compounds in water at concentrations up to the mg/L level [36], is completely degraded during water treatment with low $\mathrm{ClO}_{2}$ doses [37]. In wastewater effluents, steroid estrogens and industrial estrogenic chemicals were removed by using $\mathrm{ClO}_{2}$ doses between 1.25 and $3.75 \mathrm{mg} / \mathrm{L}$. At the same time, the reduction of estrogenic potency was observed [38]. The capability of $\mathrm{ClO}_{2}$ as an oxidant has also demonstrated in the removal of several antibiotics found in water effluents [39,40]. When $\mathrm{ClO}_{2}$ was used in biologically treated wastewater for selective oxidation of organic micropollutants, it was found that smaller doses were rapidly consumed through reactions with soluble components in water. This fast consumption in wastewater was observed in previous studies by other authors $[34,38,41]$. Based on 
$134 \mathrm{ClO}_{2}$ reactivity in wastewater effluents, it has been suggested that $\mathrm{ClO}_{2}$ could be used as an

135 alternative to ozone for the removal of micropollutants [42,43].

Taking into account all the information above mentioned, the aim of this work consists of 138 evaluating the removal efficiency of some common PCs (Ibuprofen, Acetaminophen, Diclofenac, 139 Diazepam, Clonazepam, and Sulfamethoxazole) from both model aqueous solutions and raw 140 wastewaters. As a novelty, the performance of the most often used techniques for removal PCs (UF, $141 \mathrm{NF}, \mathrm{AC}, \mathrm{SBR}$, and $\mathrm{ClO}_{2}$ ) were compared to the efficiency achieved by combining these techniques $\left(\mathrm{AC}+\mathrm{UF}, \mathrm{UF}+\mathrm{NF}, \mathrm{SBR}+\mathrm{ClO}_{2}\right)$. In addition, best techniques to remove each PC in terms of removal efficiency were suggested.

\section{MATERIALS AND METHODS}

\subsection{Pharmaceutical Compounds}

The choice of pharmaceutical compounds and their respective concentrations were performed according to their occurrence in the environment as explained above. The active principles and the main characteristics of the target PCs extracted from literature $[8,28,44-46]$ can be observed in Table 1.

The compounds selected were studied at the same concentration to simulate raw wastewater that was 1000 ng/L for Ibuprofen (Tarbis, Tarbis Farma, Spain) and Acetaminophen (Pensa, Pensa Pharma, Spain), and 300 ng/L for Diclofenac (Voltaren, Novartis Farmacéutica, Spain), Sulfamethoxazole (Septrin, UCB-Iberia, Spain), Clonazepam (Rivotril, Roche Farma, Spain) and Diazepam (Prodes, Kern Pharma, Spain).

The pure active principles were obtained using the drugs from commercially available pad. The proportionality factor between the weight of the pad and the amount of active principle contained in it was calculated. PCs quantities are presented in Table 2. The effect of the remaining quantities of 

results [47].

$184 \quad E(\%)=\left(1-\frac{C_{\text {out }}}{C_{\text {in }}}\right) \cdot 100$

\subsubsection{Ultrafiltration}

$$
E(\%)=\left(1-\frac{C_{\text {out }}}{C_{\text {in }}}\right) \cdot 100
$$
downstream of the treatment.

excipients (mainly cornstarch in small amounts) did not significantly influence on the experimental

\subsection{Membrane Processes}

The first phase of the ultrafiltration experiment was focused on the determination of the permeability coefficient. The membrane used is an IRIS one (Orelis, France), made of polyethersulfone (PES), with a molecular weight cut-off (MWCO) of $3 \mathrm{kDa}$ and an effective area of $90.28 \mathrm{~cm}^{2}$. This membrane has similar MWCO range that those used for treating PCs by other researchers [8]. Characterization experiment of UF membrane involves the determination of the coefficient of permeability with deionized water at different transmembrane pressures (from 0.5 to 4 bar). After the experiments, this coefficient had a value of $55 \mathrm{~L} / \mathrm{m}^{2} \cdot \mathrm{h} \cdot$ bar.

Experiments were carried out with two different simulate wastewaters. Wastewater Type I consisted of different solutions of each pharmaceutical compound in deionized water, whereas wastewater Type II is similar to Type I but adding bovine serum albumin (BSA) in its composition. According to Liang et al., this second model wastewater simulates a real wastewater from WWTP [48]. UF experimental set up was described previously in detail in a previous paper [49]. Permeate flux and rejection index were determined under the following operating conditions: temperature of $20{ }^{\circ} \mathrm{C}$, feed flow rate of $50 \mathrm{~L} / \mathrm{h}$ (cross-flow velocity of $0.3 \mathrm{~m} / \mathrm{s}$ ) and transmembrane pressure (TMP) of 1.5 bar. Flux and rejection measurements were performed after 1 hour (steady state conditions).

Rejection index was calculated according to the following equation (Eq. (1)):

where $C_{\text {in }}$ was the concentration upstream of the treatment and $C_{\text {out }}$ was the concentration 


\subsubsection{Nanofiltration}

NF tests were performed in a pilot plant with a spiral wound composite polyamide membrane "Hydranautics ESNA1-LF2-2540" (Nitto-Denko, Switzerland). The experimental setup where these tests were carried out was adapted to NF and was described elsewhere [50]. The characterization of this NF membrane with deionized water showed a permeability coefficient of $4 \mathrm{~L} / \mathrm{m}^{2} \cdot \mathrm{h} \cdot \mathrm{bar}$.

NF experiments were carried out at a temperature of $16.5^{\circ} \mathrm{C}$, feed flow rate of $370 \mathrm{~L} / \mathrm{h}$ and a TPM of 15 bar, with a Type I feed. In addition, $\mathrm{pH}$ was modified in order to study its effect on the removal efficiencies. Permeate flux and rejection index of each compound were determined after 30 minutes of filtration time. In a second stage, wastewater from a secondary treatment of a municipal wastewater treatment plant (MWWTP) with pharmaceutical compounds (Type III) was used as a feed solution.

After each membrane separation procedure (both UF and NF), membranes were cleaned using chemical processes (alkaline solutions at $\mathrm{pH}=10$ and citric acid at $\mathrm{pH}=3$ ) and deionized water. In this way, membrane permeabilities were re-evaluated in order to restore the initial values of permeability. Also, both UF and NF experiments were repeated three times and the average was used to evaluate the performance of these membrane processes.

\subsection{Activated Carbon}

Activated carbon was evaluated for removal of target PCs in wastewater Type II. Two commercially available AC were evaluated: Clarimex $061 \mathrm{CAE}$ and Epibon YM 12X40, both provided by Chiemivall, Spain. Experiments were performed in a Jar test (Selecta) and the average of three samples obtained for each test was used to evaluate the process performance. The doses and contact times were based on full-scale treatment plants that frequently use AC. Therefore, a contact 
time of $4 \mathrm{~h}$ followed by $60 \mathrm{~h}$ of settling and AC doses of 10 and $50 \mathrm{mg} / \mathrm{L}$ were evaluated.

214 Supernatant was collected and filtered to remove residual AC.

\subsection{Oxidation with chlorine dioxide}

Chlorine dioxide solutions with a concentration of $3000 \mathrm{mg} / \mathrm{L}$ were prepared by sequentially mixing

TwinOxide ${ }^{\circledR}$ reagents A (sodium chlorite) and B (sodium bisulphate) as it was indicated by the manufacturer (Brenntag Iberia, Spain). To study the PCs oxidation, different chloride dioxide concentrations (from 0 to $20 \mathrm{mg} / \mathrm{L}$ ) from these solutions were mixed with samples of $400 \mathrm{~mL}$ of each PCs solution (Type I). The mixed solutions were allowed to react in the dark for $17 \mathrm{~h}$ at controlled temperature $\left(22{ }^{\circ} \mathrm{C}\right)$. After the reaction was complete, three samples of $250 \mathrm{ml}$ of were taken from each reaction to be analyzed.

\subsection{Sequencing Batch Reactor}

These experiments were performed in a SBR with a total volume of $10 \mathrm{~L}$.. The reaction volume used was 6 L. It was equipped with an air pump and an air diffuser to keep dissolved oxygen (DO) above $3 \mathrm{mg} / \mathrm{L}$, and a stirrer for mixing. Feeding and decanting were performed using two peristaltic pumps. Reactor feed was a solution prepared with $4.5 \mathrm{~g}$ of peptone (Cultimed, Panreac Spain), $4.5 \mathrm{~g}$ of meat extract (Cultimed, Panreac Spain) and $0.6 \mathrm{~g}$ of phosphor dissolved in tap water (Type IV). The cycle period was divided into five phases: filling (0.5 h), aeration-reaction (6 h), settling ( $1 \mathrm{~h})$, decanting $(0.25 \mathrm{~h})$ and idle $(0.25 \mathrm{~h})$. The hydraulic retention time (HRT) for SBR experiments was 16 h. The cycle was repeated 18 times to allow cell acclimation and/or to obtain repetitive results. 234 Daily analysis of pH (Crison GLP 21+), conductivity (Crison GLP 31+), turbidity (Dinko turbidimeter d-112) and COD (kits from Merck Spain) of the supernatant were carried out. The effect of the $\mathrm{ClO}_{2}$ solutions during the SBR experiments was also tested as a combined process to be compared with SBR results. Concentration of mixed liquor suspended solids (MLSS) and mixed 238 liquor volatile suspended solids (MLVSS) were measured throughout the operation according to standard methods [51]. 
241 The initial MLSS concentration was $2.5 \mathrm{~g} / \mathrm{L}$. After one week of feeding only with the above 242 described simulated wastewater, pharmaceutical compounds were added to the feed solution once 243 biomass was acclimated to the simulated wastewater.

2.6. Analytical method for PCs analysis

2.6.1. SPE for extraction of water samples

The process SPE/clean-up used for water samples was based on that reported by Petrovic et al. [52]. PCs were isolated from water samples (250 ml, pH neutral) using an Oasis HLB cartridge [poly (divinylbenzene-co-N-pyrrolidone)] preconditioned with $5 \mathrm{~mL}$ of methanol and $5 \mathrm{~mL}$ of Milli-Q water. Samples were passed through the cartridges at a flow rate of $10 \mathrm{ml} / \mathrm{min}$ and then cartridges were rinsed with $5 \mathrm{ml}$ of Milli-Q water and dried under vacuum for 15 minutes. The analytes retained were eluted with $6 \mathrm{ml}$ of methanol. The extract was evaporated under a gentle stream of nitrogen and reconstituted with $1 \mathrm{ml}$ methanol/water (25:75, v/v), filtered using syringe poly (tetrafluoroethylene) (PTFE) filters $(0.22 \mu \mathrm{m}$, Analisis Vinicos, Tomelloso, Spain) and injected into the HPLC-MS/MS for analysis.

\subsubsection{LC-ESI-MS/MS}

An 1260 Infinity Ultra High-Performance Liquid Chromatograph (UHPLC) tandem with a 6410 Triple Quad Mass Spectrophotometer (MS/MS) is used for separating and determining, both of them of Agilent Technologies (Santa Clara, CA, USA). The analytical column was Kinetex $1.7 \mu \mathrm{m}$ XB-C18 (60 x $2.10 \mathrm{~mm})$ from Phenomenex (Paris, France). PCs were determined in both positive and negative ionization modes. In positive ionization (PI), the mobile phase was eluent A (formic acid $0.1 \%$ in methanol) and eluent B (formic acid $0.1 \%$ in water) in a gradient programme that started at $20 \%$ A for $0.1 \mathrm{~min}$, increased linearly to $90 \% \mathrm{~A}$ in $15 \mathrm{~min}$, then increased to $98 \% \mathrm{~A}$ in $15 \mathrm{~min}$, hold for $8 \mathrm{~min}$, and returned to the initial conditions after 1 min followed by 11 min of equilibration time. Flow rate used in these measurements was $0.2 \mathrm{~mL} / \mathrm{min}$. In negative ionization 
267 (NI), the mobile phase was methanol with $5 \mathrm{mM}$ ammonium formate as eluent $\mathrm{A}$ and ammonium 268 formate $5 \mathrm{mM}$ in water as eluent $\mathrm{B}$, at a flow rate of $0.2 \mathrm{~mL} / \mathrm{min}$. A gradient programme was used 269 as follows: $15 \%$ of eluent A for $0.1 \mathrm{~min}$, followed by a linear increase to $98 \%$ in 5 min, held for 7 270 min. The injection volume was $20 \mu \mathrm{L}$. Compounds optimization was carried out with Optimizer 271 program by Agilent Technologies. This program looks for the best transitions and conditions (the 272 selected ones are shown in Table 3). Optimizer was configured to search a fragmentor from 5 to 200 273 V and this can search each 10 steps. Collision energy Optimizer should search from 10 to $150 \mathrm{~V}$. NI searches preferably $[\mathrm{M}-\mathrm{H}]^{-}$whereas PI mode $[\mathrm{M}+\mathrm{H}]^{+},\left[\mathrm{M}+\mathrm{NH}_{4}\right]^{+}$and $[\mathrm{M}+\mathrm{Na}]^{+}[53]$.

\subsubsection{Validation of the analytical method}

Linearity was studied using standard solutions and matrix matched calibrations by analysing in triplicate seven concentration levels, between 7.5 and $7500 \mathrm{ng} / \mathrm{mL}$ in the final extract, equivalent to equations. Samples were spiked with the analytes at $0.5 \mu \mathrm{g} / \mathrm{L}$ for water under the conditions described above. The limit of detection (LOD) and the limit of quantification (LOQ) were calculated as the amount of the analyte with a signal-to-noise ratio (SN) of 3 and 10, respectively [54]. Method LODs are outlined in Table 4.

\section{RESULTS AND DISCUSSION}

\subsection{Results of UF process}

Table 5 shows the PCs rejection obtained during the UF tests carried out with two different simulated wastewaters (Types I and II). The value of each parameter listed in this table is an average of that obtained in three independent experiments. Results indicated low rejection values for all PCs tested using Type I feed wastewater, which are similar to those obtained by Acero et al. in UF experiments with a PES membrane of 5000 Da [55]. However, three PCs (Ibuprofen, Diclofenac and Diazepam) presented higher rejection values during UF than the other compounds tested. The behaviour showed by these PCs could be intimately related to their Log Kow (logarithm 
of the octanol-water partition coefficient), which indicates the hydrophobicity of an organic compound and it is often used to describe the sorption potential of PCs in the aquatic environment [56]. The PCs with high retention value during UF process have a Log Kow next to 3 (Diazepam) or even higher (Ibuprofen and Diclofenac), where these results are in accordance with those obtained by other researchers. Lopez-Fernandez et al. [57] demonstrated that the PC adsorption on the membrane surface (in their case, PVDF membrane) is related to the Log $K_{\text {ow }}$ value. When this value is low (<2.6), PCs have low lipophilicity and high hydrophilicity which indicates that these PCs are not adsorbed on the membrane surface (generally unmodified PVDF and PES have hydrophobic character [58,59]). On the other hand, when PCs have high Log Kow (> 4.5), the opposite effect is observed, being these compounds adsorbed on membrane surfaces [57]. Also, Yoon et al. demonstrated for UF and NF experiments that PCs with high average retention percentage had a Log $K_{\text {ow }}$ value higher than 3, which indicates that retention for hydrophobic membranes is influenced by hydrophobic interaction (adsorption) [8]. So, based on the results obtained by these researchers, the PCs could be adsorbed on the membrane surface depending on their Log Kow value. Diclofenac presented the highest rejection value and then, the highest adsorption on the surface of the PES membrane used because this molecule has the highest Log Kow value among all the PCs tested.

When Type II wastewater was used as feed solution (with BSA in its composition), slightly higher rejection values were obtained for Diazepam. However, a huge increase in rejection values was observed for Ibuprofen, Sulfamethoxazole and Diclofenac, where the latter presented the highest rejection values among all the PCs tested (42.2 \%). Chon et al. performed similar UF experiments with Diclofenac and Sulfamethoxazole, obtaining similar rejection values [45]. The increase in PCs rejection values using wastewater Type II could be due to their adsorption onto the proteins, which may form aggregates with higher size than the dissolved protein in the solution [60]. Other researchers as Sharma et al. studied the BSA interaction with two different PCs (Diclofenac sodium and Cefotaxime sodium) and they observed that the binding affinity of both PCs with BSA was 
high in a range of temperatures between 10 and $35^{\circ} \mathrm{C}$. They also demonstrated that a tighter binding BSA and Diclofenac occurred [61]. In addition, Karpii et al. corroborated that the presence of albumin in serum diminished the adsorption of PCs onto a PVDF modified membrane [46].

\subsection{Results of NF process}

NF reached high PCs removal efficiencies (between 60 and $92 \%$ ) with the exception of Acetaminophen ( 2 \%) as it is shown in Table 5. These results for this compound could be due to its low Log Kow value (0.46), as it was explained in section 3.1, its low molecular weight (151.2 $\mathrm{g} / \mathrm{mol}$ ) and its neutral charge [57]. The difference between the Acetaminophen removal and the other PCs was higher in NF because the electrostatic repulsion forces between the membrane (polyamide) and the PC exerted more influence on membrane separation than in UF processes during the removal of the rest of PCs. Unlike some results reported by other authors [55], PCs removal efficiencies obtained in this work are slightly higher, due to the low MWCO of the membrane used (between 70 and $80 \%$ of sodium chloride rejection under standard solutions according to the membrane supplier).

The influence of $\mathrm{pH}$ solution on the PCs removal was considerable, especially in the case of Clonazepam, because the reduction of $\mathrm{pH}$ from 8.5 to 6.5 led to an increase in its removal efficiency from 22 to $80 \%$ (see Table 5). Other researchers studied the $\mathrm{pH}$ influence on the rejection of PCs as one of the most important parameters that could affect the performance of UF, NF and RO membranes [45], Among all the PCs studied, the removal of Clonazepam is heavily influenced by changing the $\mathrm{pH}$ of the aquatic environment. The results for this compound reveal that the removal efficiency slightly decreased between $\mathrm{pH}$ values of 6.11 (80.33\%) and 6.48 (74.54 \%). However, this removal efficiency vastly declined to $24.81 \%$ at a $\mathrm{pH}$ value of 8.5 . According to the pKa values for Clonazepam (1.5 y 10.5) presented in Table 1, this compound is protonated at highly acidic conditions and it becomes non-protonated (neutral) when $\mathrm{pH}$ values increases up to 6, as was demonstrated in separated studies by Miri and Jalali[62] and García and Perillo[63]. But, at alkaline 
conditions, the compound changes to its enolic form, which has enhanced its affinity to water due to the presence of charge on the molecule $[62,63]$. This increase in water affinity leads to a lower retention of the PC molecule onto the membrane surface and therefore, its removal efficiency decreases.

Results of the tests performed with Type II wastewater and with secondary effluent plus PCs (Type III) are also presented in Table 5. It can be observed that NF was still slightly more effective than in the case of Type I water (80-90 \% of retention indexes). This behaviour could be explained by the interaction between PCs and organic compounds remaining in the secondary effluent, mainly proteins and carbohydrates coming from the release of cellular material. Acetaminophen was also the PC with the minimum rejection, though values were considerable higher than in the tests with synthetic solutions (55.34 \%).

\subsection{Results of the activated carbon tests}

In this section, results of the experiments with activated carbon using the source water Type II, with and without previous UF, are reported.

\subsubsection{Activated Carbon}

Table 6 shows the removal efficiency for all PCs using AC. Great removal efficiencies were obtained for both ACs, especially at high AC concentration (50 mg/L). Thus, the increase of the concentration of both activated carbons coincided with an increase in their removal efficiency, with the only exception of Diclofenac $(82.7 \% \rightarrow 70.2 \%)$ in the case of the use of Epibon (pulverized granular activated carbon). This result could be associated with the hydrophobic character of

Diclofenac (high Log $\mathrm{K}_{\mathrm{Ow}}$ ) and the competitive inhibition of BSA with Diclofenac onto the activated carbon [64]. Only Acetaminophen had poor removal efficiency with Epibon $10 \mathrm{mg} / \mathrm{L}$ (only $12.9 \%$ ). According to Delgado et al., Log Kow could be a reasonable indicator of PCs removal when adsorption was only caused by hydrophobic interactions [65]. However, it cannot be 
considered an appropriate indicator for the adsorption of several compounds, for example for whose that contain heterocyclic or aromatic nitrogen, where electrostatic interactions, chemical bounding and non specific forces between the adsorptive and the AC surface are omitted through an exclusive Log Kow approach.. In addition, the removal efficiency was mostly dependent on the volume of the largest micropores of AC, because the solvation effect may enlarge the solute molecular dimensions thus hindering its access and packing in the narrower micropores. Moreover, Ji et al. observed that the adsorption of many antibiotics probably referred to a prominent size-exclusion effect when these compounds were adsorbed onto microporous ACs, because the porous structure of commercial ACs principally consisted of micropores with irregular-shaped and modestly closed pore structures [16].

\subsubsection{Activated Carbon/Ultrafiltration combined process}

AC-UF system, which combines AC adsorption with low-pressure driven membrane filtration, showed great potential to adsorb pharmaceutical compounds (80-95\%), as it is displayed in Table 6. All views expressed previously on activated carbon remain valid, showing this technique high efficiency in all the samples analysed. It was also observed that a combined process AC+UF improves the results obtained with AC treatments, especially at low AC concentrations. For Acetaminophen, these two technologies combined in series had low removal efficiency ( 28-44 \% with $10 \mathrm{mg} / \mathrm{L}$ and $53-58 \%$ with $50 \mathrm{mg} / \mathrm{L}$ ) as already seen from the results separately obtained for UF and AC tests.

\subsection{Chlorine dioxide results}

Among the six investigated compounds, only Diazepam showed an appreciable reactivity, as it is seen in Figure 1. Results obtained for Diazepam showed that an increase in $\mathrm{ClO}_{2}$ concentration coincided with an increase in the removal efficiency, achieving values of $66 \%$. Therefore, it could be concluded that $\mathrm{ClO}_{2}$ applied in water treatment only acted as a partial barrier for PCs, even though it is relatively effective in oxidizing antibiotics and estrogens. These two compounds merit 
special concern due to their high biological activity. This is in accordance with the results reported by Huber et al., even though results are not fully comparable, because they investigated three different water sources (drinking water, lake water, groundwater) and used different experimental conditions: lower $\mathrm{ClO}_{2}$ concentrations, variable time reaction, and higher compounds concentration $(\sim \mu \mathrm{g})$ [37]. However, they obtained good removal values for Sulfamethoxazole and Diclofenac, justifying according to the reactivity of the aniline group (contained in both compounds) to $\mathrm{ClO}_{2}$ and because the deprotonation of acidic nitrogen of the sulfonamide moiety enhanced the reactivity of Sulfamethoxazole. Hey et al. investigated several compounds, but they do not study Diazepam and they also used higher concentrations (100 mg). The poor efficiency of this treatment could be due to the lower concentration used and the dependence of the degree of oxidation on the type of wastewater. Furthermore, reactivity of the compounds depended on the reactive functional group present [66].

\subsection{SBR results}

This type of treatment had different results depending on the pharmaceutical component analysed. SBR results without and with $\mathrm{ClO}_{2}$ in terms of removal efficiency were presented in Table 7. Good results for Ibuprofen and Acetaminophen ( 90-95 \% for both compounds) were observed, whereas scarce removal efficiencies were shown for Diclofenac ( 25\%), Sulfamethoxazole ( 20\%), and Diazepam ( $\sim 15 \%)$. Regarding the Clonazepam, removal efficiency presented very acceptable results ( $85 \%)$. During the operation time of all of these processes, MLSS, MLVSS, pH, conductivity, turbidity and COD were also measured and their results are shown in Table 8. Before the addition of $\mathrm{ClO}_{2}$, the different parameters measured during SBR tests did not change significantly. After the addition of $\mathrm{ClO}_{2}$ to $\mathrm{SBR}$, an initial decrease in biomass parameters as well as an increase in conductivity was detected. In the same way, the presence of $\mathrm{ClO}_{2}$ led to a general increase in the removal efficiency in the first days of treatment. There are no similar data present in literature, in fact Elmolla and Chaudhuri investigated different PCs (Amoxicillin and Cloxacillin), at different working conditions (1.5 L in volume and a biomass concentration of $2300 \mathrm{mg} / \mathrm{L}$ ) and 
with Fenton pre-treatment system. They defined the best operating conditions for treatment of the antibiotic wastewater by combined Fenton-SBR process, which were $\mathrm{H}_{2} \mathrm{O}_{2} / \mathrm{COD}$ molar ratio 2.5, $\mathrm{H}_{2} \mathrm{O}_{2} / \mathrm{Fe}^{2+}$ molar ratio 150, Fenton reaction time $120 \mathrm{~min}$ and a HRT of $12 \mathrm{~h}$. Under these conditions, they obtained a removal efficiency of $89 \%$ for COD removal and the SBR effluent met the discharge standards [67].

\subsection{Results for single compound}

This section has the aim of summarizing all the results obtained for each PC studied, which are displayed in Tables 5-7. In this way, it will be clear which processes may be the most effective for their separation.

Ibuprofen had very poor percentages of removal with UF treatments (36.33\%), but excellent removals when UF is combined with NF ( $\geq 99 \%)$. These results are higher than those obtained using only NF (75-90\%). Excellent results were also obtained with AC treatments at high AC concentration ( $\geq 95 \%$ ), and with SBR during the first days of the cycle ( $\geq 95 \%)$.

Acetaminophen had generally low removal efficiencies using NF experiments at different pHs $(\leq 13$ \%). These results could be attributed to its low molecular weight and its low value of Log Kow (values displayed in Table 1), as it was explained in sections 3.1 and 3.2. UF processes were also ineffective ( $\sim 1.6 \%)$, in contrast to SBR results, which presented high percentages of removal $(\leq 95$ \%).

For Diclofenac, AC+UF had excellent removal efficiencies ( $\geq 95 \%$ ), which were better than those obtained when both processes were individually implemented ( $\geq 68 \%$ for AC and $42.2 \%$ for UF). The same trend is observed for the combination of UF+NF, which gave excellent results ( $\geq 98 \%)$. SBR processes (with and without $\mathrm{ClO}_{2}$ ) had very low removal efficiencies ( 10-38 \%). 
The AC treatments applied for removal Sulfamethoxazole had good removal efficiencies, especially excellent results were obtained at high AC concentrations ( $\geq 92 \%)$. These results improved when AC was combined with a UF process ( 96-99 \% with $50 \mathrm{mg} / \mathrm{L})$. UF treatments had poor efficiency ( 10-21\%), while NF processes presented excellent results ( 70-98\%). Regarding the results for SBR processes (with and without $\mathrm{ClO}_{2}$ ), very low removal efficiencies ( 19-40\%) were obtained.

For the benzodiazepines studied, Clonazepam had excellent removal efficiencies during NF treatment of real wastewater ( $\geq 90 \%$ ) and at $\mathrm{pH}$ next to 6 ( $\geq 74 \%$ ), but these values decreased to $25 \%$ at $\mathrm{pH}=8.5$ when this compound changed to a enolic form (as it was indicated in section 3.2). Regarding the SBR results, they suggested an increase in the efficiency of removal during the course of the days ( $70-85 \%$ ), but in the case of introduction of $\mathrm{ClO}_{2}$ the long-term interaction with the biomass decreased and consequently the effectiveness of removal (41.5\%). In the case of Diazepam, it had excellent removal percentages when was treated using NF process ( $\geq 88 \%)$, AC treatment at low concentrations ( $\geq 93 \%$ ), but poor efficiencies with UF ( 19\%). Among all the PCs tested, this compound is the only one that showed an increase in the removal efficiency using $\mathrm{ClO}_{2}$, which increased when $\mathrm{ClO}_{2}$ concentration was higher. Finally, poor results were obtained with SBR processes ( $\sim 15 \%$ without $\mathrm{ClO}_{2}$ and $\sim 39 \%$ with $\mathrm{ClO}_{2}$ ).

\section{CONCLUSIONS}

The removal efficiency of six different pharmaceuticals using several separation techniques was studied to determine the most appropriate method for each pharmaceutical. In the case of membrane processes, UF was practically ineffective for all the compounds tested, obtaining the best removal efficiencies for all compounds using NF process, except for Acetaminophen and Ibuprofen. Both compounds presented the highest removal percentages with SBR, but this treatment had lower removal efficiencies for the remaining pharmaceuticals, for which NF process was better. As regards the AC tests, these experiments had excellent removal efficiency for almost all the pharmaceuticals examined (especially at high AC concentration, $50 \mathrm{mg} / \mathrm{L}$ ), except for 
Acetaminophen. Therefore, Acetaminophen is the pharmaceutical compound with most difficulties to be treated, due to the low effect of the treatments used along this study. In addition, Diazepam is the only compound that showed an increase of the removal efficiency with $\mathrm{ClO}_{2}$. Also, an increase in $\mathrm{ClO}_{2}$ concentration gradually led to a better removal results. Finally, the combined UF+NF process was the most effective of all the treatments performed.

For all pharmaceuticals, a general trend appeared with higher mass recovery at high Log Kow. Although experimental and analytical accuracy could vary the mass recovery, these results indicated that observed retention for the relatively hydrophobic compounds based on their Log Kow was significantly governed by adsorption.

\section{ACKNOWLEDGEMENTS}

The authors of this work wish to gratefully acknowledge the financial support from the Spanish Ministry of Economy and Competitiveness through the project CTM2013-42342-P.

\section{REFERENCES}

[1] R. Rosal, A. Rodríguez, J.A. Perdigón-Melón, A. Petre, E. García-Calvo, M.J. Gómez, A. Agüera, A.R. Fernández-Alba, Occurrence of emerging pollutants in urban wastewater and their removal through biological treatment followed by ozonation, Water Res. 44 (2010) 578-588.

[2] A.L. Batt, S. Kim, D.S. Aga, Enhanced biodegradation of iopromide and trimethoprim in nitrifying activated sludge, Environ. Sci. Technol. 40 (2006) 7367-7373.

[3] E.M Golet, A.C. Alder, W. Giger, Environmental exposure and risk assessment of fluoroquinolone antibacterial agents in wastewater and river water of the Glatt Valley Watershed, Switzerland, Environ. Sci. Technol. 36 (2002) 3645-3651.

[4] S. Schmidt, J. Winter, C. Gallert, Long-term effects of antibiotics on the elimination of chemical oxygen demand, nitrification, and viable bacteria in laboratory-scale wastewater treatment plants, Arch. Environ. Contam. Toxicol. 63 (2012) 354-364. 
[5] W. Giger, A.C. Alder, E.M. Golet, H.P.E. Kohler, C.S. McArdell, E. Molnar, H. Siegrist, M.J.F

Suter, Occurrence and fate of antibiotics as trace contaminants in wastewaters, sewage sludges, and surface waters. Chimia 57 (2003) 485-491.

[6] B. Kasprzyk-Hordern, R.M. Dinsdale, A.J. Guwy, The removal of pharmaceuticals, personal care products, endocrine disruptors and illicit drugs during wastewater treatment and its impact on the quality of receiving waters, Water Res. 43 (2009) 363-380.

[7] J. Cho, G. Amy, J. Pellegrino, Membrane filtration of natural organic matter: initial comparison of rejection and flux decline characteristics with ultrafiltration and nanofiltration membranes, Water Res. 33 (1999) 2517-2526.

[8] Y. Yoon, P. Westerhoff, S.A. Snyder, E.C. Wert, J. Yoon, Removal of endocrine disrupting compounds and pharmaceuticals by nanofiltration and ultrafiltration membranes, Desalination 202 (2007) 16-23.

[9] Y. Kiso, Y. Sugiura, T. Kitao, K. Nishimura, Effects of hydrophobicity and molecular size on rejection of aromatic pesticides with nanofiltration membranes, J. Membr. Sci. 192 (2001) 1-10.

[10] B. Van der Bruggen, K. Everaert, D. Wilms, C. Vandecasteele, The use of nanofiltration for the removal of pesticides from groundwater: an evaluation, Wa. Sci. Technol. 1 (2001) 99-106.

[11] K. Kimura. G. Amy, J.E. Drewes, T. Heberer, T.U. Kim, Y. Watanabe, Rejection of organic micropollutants (disinfection by-products, endocrine disrupting compounds, and pharmaceutically active compounds) by NF/RO membranes, J. Membr. Sci. 227 (2003) 113-121.

[12] L.D. Nghiem, A.I. Schafer, M. Elimelech, Removal of natural hormones by nanofiltration membranes; measurement modelling, and mechanism, Environ. Sci. Technol. 38 (2004) 1888-1896. [13] A.M. Comerton, R.C. Andrews, D.M. Bagley, C. Hao, The rejection of endocrine disrupting and pharmaceutically active compounds by NF and RO membranes as a function of compound and water matrix properties, J. Membr. Sci. 313 (2008) 323-335.

[14] K. Kimura, G. Amy, J. Drewes, Y. Watanabe, Adsorption of hydrophobic compounds onto NF/RO membranes: an artifact leading to overestimation of rejection, J. Membr. Sci. 221 (2003) 89-101. 
[15] L.D. Nghiem, A.I. Schafer, M. Elimelech, Pharmaceutical retention mechanisms by nanofiltration membranes, Environ. Sci. Technol. 39 (2005) 7698-7705.

[16] L. Ji, F. Liu, Z. Xu, S. Zheng, D. Zhu, Adsorption of pharmaceutical antibiotics on templatesynthesized ordered micro and mesoporous carbons, Environ Sci. Technol. 44 (2010) 3116-3122.

[17] K. Mohanty, D. Das, M.N. Biswas, Preparation and characterization of activated carbons from sterculia alata nutshell by chemical activation with zinc chloride to remove phenol from wastewater, Adsorption 12 (2006) 119-132.

[18] J.E. Kilduff, T. Karanfil, W.J. Weber, Competitive interactions among components of humic acids in granular activated carbon adsorption systems: effects of solution chemistry, Environ Sci. Technol. 30 (1996) 1344-1351.

[19] A. Dabrowski, P. Podkoscielny, Z. Hubicki, M. Barczak, Adsorption of phenolic compounds by activated carbon: a critical review, Chemosphere 58 (2005) 1049-1070.

[20] L. Li, P.A. Quinlivan, D.R.U. Knappe, Effects of activated carbon surface and pore structure on the adsorption of organic contaminants from aqueous solution, Carbon 40 (2002) 2085-2100.

[21] B. Ruiz, I. Cabrita, A.S. Mestre, J.B. Parra, J. Pires, A.P. Carvalho, C.O. Ania, Surface heterogeneity effects of activated carbons on the kinetics of acetaminophen removal from aqueous solution, Appl. Surf. Sci. 256 (2010) 5171-5175.

[22] G. Newcombe, M. Drikas, R. Hayes, Influence of characterised natural organic material on activated carbon adsorption: II. Effect on pore volume distribution and adsorption of 2methylisoborneol, Water Res. 31 (1997) 1065-1073.

[23] I. Bautista-Toledo, M.A. Ferro-García, J. Rivera-Utrilla, C. Moreno-Castilla, J. VegasFernández, Bisphenol A removal from water by activated carbon: effects of carbon characteristics and solution chemistry, Environ Sci. Technol. 39 (2005) 6246-6250.

[24] A.S.Mestre, J. Pires, J.M.F. Nogueira, J.B. Parra, A.P. Carvalho AP, C.O. Ania, Waste-derived activated carbons for removal of ibuprofen from solution: role of surface chemistry and pore structure, Bioresource Technol. 100 (2009) 1720-1726. 
[25] T. Karanfil, J. E. Kilduff, Role of granular activated carbon surface chemistry on the adsorption of organic compounds. 1. Priority pollutants, Environ. Sci. Technol. 33 (1999) 32173224.

[26] M. Fuerhacker, A. Dürauer, A. Jungbauer, Adsorption isotherms of 17ß-estradiol on granular activated carbon (GAC), Chemosphere 44 (2001) 1573-1579.

[27] P. Westerhoff, Y. Yoon, S. Snyder, E. Wert, Fate of endocrine-disruptor, pharmaceutical, and personal care product chemicals during simulated drinking water treatment processes, Environ. Sci. Technol. 39 (2005) 6649-6643.

[28] S.A. Snyder, S. Adham, A.M. Redding, F.S. Cannon, J. De Carolis, J. Oppenheimer, E.C. Wert, Y. Yoon, Role of membranes and activated carbon in the removal of endocrine disruptors and pharmaceuticals, Desalination 202 (2007) 156-181.

[29] C. Moreno-Castilla, J. Rivera-Utrilla, J.P. Joly, M.V. López-Ramon, M.A. Ferro-García, F. Carrasco-Marín, Thermal regeneration of an activated carbon exhausted with different substituted phenols, Carbon 33 (1995) 1417-1423.

[30] J. Rivera-Utrilla, M.A. Ferro-García, I. Bautista-Toledo, C. Sánchez-Jiménez, F. Salvador, M.D. Merchán, Regeneration of ortho-chlorophenol-exhausted activated carbons with liquid water at high pressure and temperature, Water Res. 37 (2003) 1905-1911.

[31] Report Roskill, The economics of activated carbon, 7th ed, London: Roskill Information Services, 2003, p 193.

[32] S. Mace, J. Mata-Alvarez, Review of SBR technology for wastewater treatment: an overview, Ind. Eng. Chem. Res. 41 (2002) 5539-5553.

[33] A. Chiavola, R. Baciocchi, R. Gavasci, Biological treatment of PAH-contaminated sediments in a sequencing batch reactor, J. Hazard. Mater. 184 (2010) 97-104.

[34] Y. Lee, U. von Gunten, Oxidative transformation of micropollutants during municipal wastewater treatment: comparison of kinetic aspects of selective (chlorine, chlorine dioxide, ferrate VI, and ozone) and non-selective oxidants (hydroxyl radical), Water Res. 44 (2010) 555-566. 
[35] F.J. Benitez, J.L. Acero, F.J. Real, G. Roldan, F. Casas, Comparison of different chemical oxidation treatments for the removal of selected pharmaceuticals in water matrices, Chem. Eng. J. 168 (2011) 1149-1156.

[36] T.A. Ternes, Occurrence of drugs in German sewage treatment plants and rivers, Water Res. 32 (1998) 3245-3260.

[37] M.M. Huber, S. Korhonen, T.A. Ternes, U. von Gunten, Oxidation of pharmaceuticals during water treatment with chlorine dioxide, Water Res. 39 (2005) 3607-3617.

[38] H.R. Andersen, Use of $\mathrm{ClO}_{2}$ for removal of estrogenic substances in wastewater, Patent WO2010/023311, 2010 Mar 4.

[39] S. Navalon, M. Alvaro, H. Garcia, Reaction of chlorine dioxide with emergent water pollutants: product study of the reaction of three $\beta$-lactam antibiotics with $\mathrm{ClO}_{2}$, Water Res. 42 (2008) 1935-1942.

[40] P. Wang, Y.L. He, C.H. Huang, Oxidation of fluoroquinolone antibiotics and structurally related amines by chlorine dioxide: reaction kinetics, product and pathway evaluation, Water Res. 44 (2010) 5989-5998.

[41] G. Hey, A. Ledin, J.L. Jansen, H.R. Andersen, Removal of pharmaceuticals in biologically treated wastewater by chlorine dioxide or peracetic acid, Environ. Technol 33 (2012) 1041-1047.

[42] K.M. Hansen, H.R. Andersen, A. Ledin, Ozonation of estrogenic chemicals in biologically treated sewage, Water Sci. Technol. 62 (2010) 649-657.

[43] A. Ried, J. Mielcke, A. Wieland, The potential use of ozone in municipal wastewater, OzoneSci. Eng. 31 (2009) 415-421.

[44] L. Ferrando-Climent, N. Collado, G. Buttiglieri, M. Gros, I. Rodríguez-Roda, S. RodríguezMozaz, D. Barceló, Comprehensive study of ibuprofen and its metabolites in activated sludge batch experiments and aquatic environment, Sci. Total Environ. 438 (2012) 404-413.

[45] K. Chon, J. Cho, H.K. Shon, A pilot-scale hybrid municipal wastewater reclamation system using combined coagulation and disk filtration, ultrafiltration, and reverse osmosis: Removal of 
nutrients and micropollutants, and characterization of membrane foulants, Bioresource Technol. 141 (2013) 109-116.

[46] J. Karpii, S. Åkerman, K. Åkerman, A. Sundell, K. Nyyssönen, I. Penttilä, Adsorption of drugs onto a $\mathrm{pH}$ responsive poly(N,N-dimethyl aminoethyl methacrylate) grafted anion-exchange membrane in vitro, Int. J. Pharm. 338 (2007) 7-14.

[47] C. Carlsson, A. K. Johansson, G. Alvan, K. Bergman, T. Kühler, Are pharmaceuticals potent environmental pollutants? Part II: Environmental risk assessments of selected pharmaceutical excipients, Sci. Total Environ. 364 (2006) 88-95.

[48] S. Liang, G. Qi, K. Xiao, J. Sun, E.P. Giannelis, X. Huang, M. Elimelech, Organic fouling behavior of superhydrophilic polyvinylidene fluoride (PVDF) ultrafiltration membranes functionalized with surface-tailored nanoparticles: implications for organic fouling in membrane bioreactors, J. Membr. Sci. 463 (2014) 94-101.

[49] J. Garcia-Ivars, M.I. Alcaina-Miranda, M.I. Iborra-Clar, J.A. Mendoza-Roca, L. PastorAlcañiz, Enhancement in hydrophilicity of different polymer phase-inversion ultrafiltration membranes by introducing PEG/Al $\mathrm{O}_{3}$ nanoparticles, Sep. Purif. Technol. 128 (2014) 45-57.

[50] M.I. Alcaina-Miranda, S. Barredo-Damas, A. Bes-Piá, M.I. Iborra-Clar, A. Iborra-Clar, J.A. Mendoza-Roca, Desalination 240 (2009) 290-297.

[51] A.D. Eaton, M.A.H. Franson, Standard methods for the examination of water and wastewater, American Public Health Association (2005), ISBN-13: 9780875530475

[52] M. Petrovic, A. Diaz, F. Ventura, D. Barceló, Simultaneous determination of halogenated derivatives of alkylphenol ethoxylates and their metabolites in sludges, river sediments, and surface, drinking, and wastewaters by liquid chromatography-mass spectroscopy, Anal Chem. 73(24) (2001) 5886-5895.

[53] P. Vázquez-Roig, V. Andreu, M. Onghena, C. Blasco, Y. Picó, Assessment of the occurrence and distribution of pharmaceuticals in a Mediterranean wetland (L’Albufera, Valencia, Spain) by LC-MS/MS, Anal. Bioanal. Chem. 400 (2011) 1287-1301. 
641 [54] E. Carmona, V. Andreu, Y. Picó, Occurrence of acidic pharmaceuticals and personal care 642 products in Turia River Basin: from waste to drinking water, Sci. Total Environ. 484 (2014) 53-63. 643 [55] J.L. Acero, F.J. Benítez, F. Teva, A.I. Leal, Retention of emerging micropollutants from UP 644 water and a municipal secondary effluent by ultrafiltration and nanofiltration, Chem. Eng. J. 163 645 (2010) 264-272.

646 [56] V. Burke, S. Treumann, U. Duennbier, J. Greskowiak, G. Massmann, Sorption behavior of 20 647 wastewater originated micropollutants in groundwater - column experiments with pharmaceutical 648 residues and industrial agents, J. Contam. Hydrol. 154 (2013) 29-41.

649 [57] R. López Fernández, J.A. McDonald, S.J. Khan, P. Le-Clech, Removal of pharmaceuticals and 650 endocrine disrupting chemicals by a submerged membrane photocatalysis reactor (MPR), Sep. 651 Purif. Technol. 127 (2014) 131-139.

652 [58] G.-D. Kang, Y.-M. Cao. Application and modification of poly(vinylidene fluoride) (PVDF) 653 membranes - a review, J. Membr. Sci. 463 (2014) 145-165.

654 [59] J. García-Ivars, M.-I. Iborra-Clar, M.-I. Alcaina-Miranda, J.-A. Mendoza-Roca, L. Pastor655 Alcañiz, Development of fouling-resistant polyethersulfone ultrafiltration membranes via surface 656 UV photografting with polyethylene glycol/aluminum oxide nanoparticles, Sep. Purif. Technol. 135 657 (2014) 88-99.

658 [60] J. Chen, X.Y. Jiang, X.Q. Chen, Y. Chen, Effect of temperature on the metronidazole-BSA 659 interaction: multi-spectroscopic method, J. Membr. Sci. 876 (2008) 121-126.

660 [61] R. Sharma, S. Choudhary, N. Kishore, Insights into the binding of the drugs diclofenac sodium 661 and ceftotaxime sodium to serum albumin: calorimetry and spectroscopy, Eur. J. Pharm. Sci. 46(5) 662 (2012) 435-445.

663 [62] L. Miri, F. Jalali, Dispersive liquid-liquid micro-extraction as a sample preparation method for 664 Clonazepam analysis in water samples and pharmaceutical preparations, Journal of Reports in 665 Pharmaceutical Sciences 2(2) (2013) 103-110.

666 [63] D.A. García, M.A. Perillo, Benzodiazepine localisation at the lipid-water interface: effect of 667 membrane composition and drug chemical structure, BBA-Biomembranes 1418 (1999) 221-231. 
668 [64] S.-W. Nam, D.-J. Choi, S.-K. Kim, N. Her, K.-D. Zoh, Adsorption characteristics of selected 669 hydrophilic and hydrophobic micropollutants in water using activated carbon, J. Hazard. Mater. 270 $670 \quad$ (2014) 144-152.

671 [65] L.F. Delgado, P. Charles, K. Glucina, C. Morlay, The removal of endocrine disrupting 672 compounds, pharmaceutically activated compounds and cyanobacterial toxins during drinking water 673 preparation using activated carbon - a review, Sci. Total Environ. 435-436 (2012) 509-525.

674 [66] G. Hey, R. Grabic, A. Ledin, J.L. Jansen, H.R. Andersen, Oxidation of pharmaceuticals by 675 chlorine dioxide in biologically treated wastewater, Chem. Eng. J. 185-186 (2012) 236-242.

676 [67] E.S. Elmolla, M. Chaudhuri, The feasibility of using combined Fenton-SBR for antibiotic 677 wastewater treatment, Desalination 285 (2012) 14-21. 
Table 1. Main characteristics of the selected pharmaceuticals used in this study.

\begin{tabular}{|c|c|c|c|c|c|}
\hline $\begin{array}{l}\text { Pharmaceutical } \\
\text { compound }\end{array}$ & Structure & $\begin{array}{c}\text { Molecular } \\
\text { weight } \\
\text { (g/mol) }\end{array}$ & $\log K_{o w}$ & pKa & Ref. \\
\hline Ibuprofen & & 206.29 & 3.97 & 4.91 & [44] \\
\hline Acetaminophen & & 151.2 & 0.46 & 9.4 & [8] \\
\hline Diclofenac & & 296.14 & 4.51 & 4.15 & [45] \\
\hline Sulfamethoxazole & & 253.28 & 0.89 & 5.5 & [28] \\
\hline Clonazepam & & 315.71 & 2.41 & $\begin{array}{c}10.5 \text { (1-position) } \\
1.5 \text { (4-position) }\end{array}$ & [46] \\
\hline Diazepam & & 284.80 & 2.82 & 3.3 & [8] \\
\hline
\end{tabular}

Table 2. Active principle and quantities of the pharmaceuticals used.

\begin{tabular}{ccccc}
\hline Pharmaceutical names & Active principle & $\begin{array}{c}\text { Weight a single } \\
\text { pad (mg) }\end{array}$ & $\begin{array}{c}\text { Weight active principle } \\
\text { for pad (mg) }\end{array}$ & $\begin{array}{c}\text { Proportional } \\
\text { parameter }\end{array}$ \\
\hline Tarbis & Ibuprofen & 771.3 & 600 & 1.2855 \\
Acetaminophen Pensa & Acetaminophen & 1308.4 & 1000 & 1.3084 \\
Voltaren & Diclofenac & 210.9 & 50 & 4.218 \\
Septrin & Sulfamethoxazole & 501.6 & 400 & 1.254 \\
Rivotril & Clonazepam & 153.8 & 0.5 & 307.6 \\
Diazepan Prodes & Diazapem & 77.7 & 2.5 & 31.08 \\
\hline
\end{tabular}


Table 3. Experimental parameters of the analytical method used.

\begin{tabular}{ccccccc}
\hline Compound & $\begin{array}{c}\text { Frag } \\
(\mathbf{V})\end{array}$ & $\begin{array}{c}\text { Quantification } \\
\text { transition }\end{array}$ & $\begin{array}{c}\text { CE } \\
(\mathbf{V})\end{array}$ & $\begin{array}{c}\text { Frag } \\
(\mathbf{V})\end{array}$ & $\begin{array}{c}\text { Confirmation } \\
\text { transition }\end{array}$ & $\begin{array}{c}\text { CE } \\
\text { (V) }\end{array}$ \\
\hline PI Mode & & & & & & \\
Diazepam & 156 & $285 \rightarrow 193$ & 34 & 156 & $285 \rightarrow 154$ & 26 \\
$\begin{array}{c}\text { Clonazepam } \\
\text { Acetaminophen }\end{array}$ & 136 & $316 \rightarrow 270$ & 24 & 136 & $316 \rightarrow 214$ & 35 \\
Sulfamethoxazole & 112 & $152 \rightarrow 110$ & 13 & 112 & $152 \rightarrow 65$ & 33 \\
NI Mode & 104 & $254 \rightarrow 156$ & 10 & 104 & $254 \rightarrow 92$ & 26 \\
Ibuprofen & 68 & $205 \rightarrow 161$ & 2 & & & - \\
Diclofenac & 88 & $294 \rightarrow 249$ & 10 & 88 & $294 \rightarrow 178$ & 22 \\
\hline
\end{tabular}

Table 4. Limit of detection values (LOD) for all the compounds tested.

\begin{tabular}{cc}
\hline Compound & LOD \\
\hline Ibuprofen & $6.8 \mathrm{ng} / \mathrm{L}$ \\
Diazepam & $0.3 \mathrm{ng} / \mathrm{L}$ \\
Clonazepam & $0.5 \mathrm{ng} / \mathrm{L}$ \\
Acetaminophen & $0,9 \mathrm{ng} / \mathrm{L}$ \\
Diclofenac & $2,5 \mathrm{ng} / \mathrm{L}$ \\
Sulfamethoxazole & $0,9 \mathrm{ng} / \mathrm{L}$ \\
\hline
\end{tabular}

Table 5. Removal efficiencies (\%) for each selected pharmaceutical compound using different membrane separation processes and wastewaters (Type I, II and III).

\begin{tabular}{|c|c|c|c|c|c|c|c|}
\hline \multirow{2}{*}{$\begin{array}{l}\text { Pharmaceutical } \\
\text { compound }\end{array}$} & \multicolumn{2}{|c|}{ UF } & \multicolumn{4}{|c|}{ NF } & \multirow{2}{*}{$\begin{array}{c}\mathrm{UF}+\mathrm{NF} \\
\text { Type II }\end{array}$} \\
\hline & Type I & Type II & $\begin{array}{c}\text { Type I } \\
(\mathrm{pH}=6.11)\end{array}$ & $\begin{array}{c}\text { Type I } \\
(\mathrm{pH}=6.48)\end{array}$ & $\begin{array}{c}\text { Type I } \\
(\mathrm{pH}=8.5)\end{array}$ & Type III & \\
\hline Ibuprofen & 12.21 & 26.33 & 80.51 & 86.57 & 91.38 & 87.18 & 95.18 \\
\hline Diazepam & 18.98 & 19.14 & 87.41 & 90.96 & 91.28 & 91.37 & 99.69 \\
\hline Acetaminophen & Non detected & 1.60 & 1.62 & 4.91 & 12.60 & 55.34 & 76.50 \\
\hline Sulfamethoxazole & 10.70 & 20.80 & --- & 70.78 & --- & 98.21 & 99.90 \\
\hline Clonazepam & --- & --- & 80.33 & 74.54 & 24.81 & 90.32 & --- \\
\hline Diclofenac & 24.70 & 42.20 & 66.91 & 68.69 & 76.45 & 82.99 & 98.14 \\
\hline
\end{tabular}

Table 6. Removal efficiencies (\%) for each selected pharmaceutical compound using two different activated carbons (Clarimex and Epibon) and a combined hybrid process (activated carbon and ultrafiltration).

\begin{tabular}{|c|c|c|c|c|c|c|c|c|}
\hline \multirow[b]{2}{*}{$\begin{array}{l}\text { Pharmaceutical } \\
\text { compound }\end{array}$} & \multicolumn{4}{|c|}{ AC } & \multicolumn{4}{|c|}{$\mathbf{A C}+\mathbf{U F}$} \\
\hline & $\begin{array}{l}\text { Clarimex } \\
(10 \mathrm{mg} / \mathrm{L})\end{array}$ & $\begin{array}{c}\text { Clarimex } \\
(50 \mathrm{mg} / \mathrm{L})\end{array}$ & $\begin{array}{c}\text { Epibon } \\
(10 \mathrm{mg} / \mathrm{L})\end{array}$ & $\begin{array}{c}\text { Epibon } \\
(50 \mathrm{mg} / \mathrm{L})\end{array}$ & $\begin{array}{l}\text { Clarimex } \\
(10 \mathrm{mg} / \mathrm{L})\end{array}$ & $\begin{array}{c}\text { Clarimex } \\
(50 \mathrm{mg} / \mathrm{L})\end{array}$ & $\begin{array}{c}\text { Epibon } \\
(10 \mathrm{mg} / \mathrm{L})\end{array}$ & $\begin{array}{c}\text { Epibon } \\
\text { (50 mg/L) }\end{array}$ \\
\hline Ibuprofen & 43.02 & 99.00 & 77.20 & 95.35 & 63.72 & 99.90 & 85.48 & 97.04 \\
\hline Acetaminophen & 32.10 & 43.00 & 12.90 & 48.60 & 44.00 & 53.00 & 28.20 & 57.60 \\
\hline Sulfamethoxazole & 54.00 & 92.30 & 71.90 & 94.20 & 67.90 & 94.60 & 80.40 & 96.00 \\
\hline Diclofenac & 68.00 & 99.00 & 82.70 & 70.20 & 95.80 & 99.90 & 97.80 & 96.10 \\
\hline
\end{tabular}


Table 7. Removal efficiencies (\%) for each selected pharmaceutical compound using SBR and $\mathrm{SBR}+\mathrm{ClO}_{2}$ processes.

\begin{tabular}{cccccc}
\hline Pharmaceutical & \multicolumn{3}{c}{ SBR } & \multicolumn{3}{c}{ SBR + CIO } \\
compound & $\mathbf{4}^{\text {th }}$ day & $\mathbf{8}^{\text {th }}$ day & $\mathbf{1}^{\text {st }} \mathbf{d a y}$ & $\mathbf{4}^{\text {th }}$ day & $\mathbf{8}^{\text {th }}$ day \\
\hline Ibuprofen & 89.40 & 94.59 & 90.35 & 96.08 & 93.74 \\
Diazepam & 2.78 & 15.22 & 39.27 & 30.11 & 13.95 \\
Acetaminophen & 94.19 & 90.55 & 97.46 & 95.79 & 54.40 \\
Sulfamethoxazole & 19.21 & 20.33 & 29.91 & 40.54 & 25.64 \\
Clonazepam & 52.54 & 84.93 & 71.87 & 72.11 & 41.50 \\
Diclofenac & 10.29 & 25.93 & 10.58 & 37.56 & 25.96 \\
\hline
\end{tabular}

Table 8. SBR experimental results.

\begin{tabular}{cccccccc}
\hline Day of process & $\begin{array}{c}\text { MLSS } \\
{[\mathbf{m g} / \mathbf{L}]}\end{array}$ & $\begin{array}{c}\text { MLVSS } \\
{[\mathbf{m g} / \mathbf{L}]}\end{array}$ & $\begin{array}{c}\text { volatile } \\
{[\%]}\end{array}$ & $\mathbf{p H}$ & $\begin{array}{c}\text { Conductivity } \\
{\left[\mathbf{\mu S} / \mathbf{c m}^{2}\right]}\end{array}$ & $\begin{array}{c}\text { Turbidity } \\
{[\mathbf{N T U ]}}\end{array}$ & $\begin{array}{c}\text { COD } \\
{[\mathbf{m g} / \mathbf{L}]}\end{array}$ \\
\hline 1 & 1.175 & 0.993 & 84.511 & - & - & - & - \\
2 & 1.098 & 0.960 & 87.432 & 7.30 & 1070 & 10.70 & - \\
3 & 1.999 & 1.775 & 88.794 & 7.16 & 1035 & - & - \\
4 & 2.311 & 2.009 & 86.932 & 7.05 & 1017 & - & - \\
7 (pharma) & 2.784 & 2.376 & 85.345 & 7.18 & 1032 & 2.02 & 16.90 \\
8 & 2.876 & 2.558 & 88.943 & 7.18 & 1045 & - & - \\
9 & 2.833 & 2.495 & 88.069 & 7.73 & 1064 & - & - \\
10 (after purge) & 2.408 & 2.208 & 91.694 & 7.12 & 1042 & - & - \\
11 & 2.763 & 2.514 & 90.988 & 7.55 & 1062 & - & - \\
14 (ClO ${ }_{2}$ ) & 2.758 & 2.562 & 92.893 & 7.57 & 1009 & 2.58 & 18 \\
15 & 2.754 & 2.478 & 89.978 & 7.45 & 1053 & - & - \\
16 & 2.539 & 2.277 & 89.681 & 7.70 & 1141 & - & - \\
17 & 2.333 & 2.120 & 90.870 & 7.69 & 1133 & - & - \\
18 (after purge) & 2.518 & 2.258 & 89.674 & 7.60 & 1134 & - & - \\
21 & 2.641 & 2.350 & 88.981 & 7.33 & 1068 & 3.95 & 20.05 \\
\hline
\end{tabular}




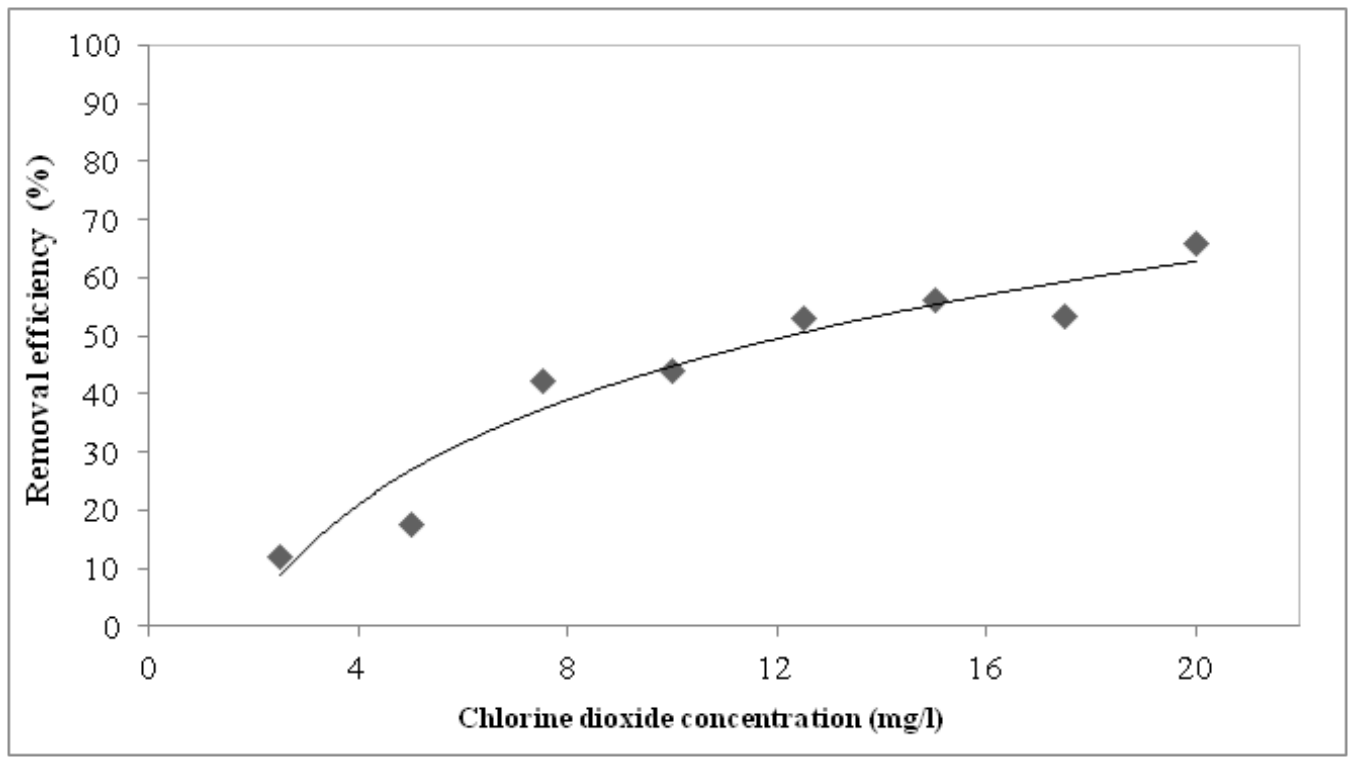

Figure 1. Removal efficiencies (\%) of Diazepam at different $\mathrm{ClO}_{2}$ concentrations. 